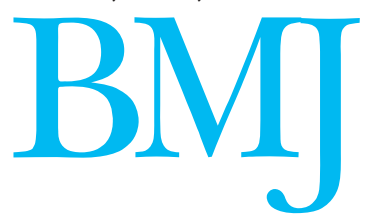

\title{
Informal care giving for disabled stroke survivors
}

\author{
Training the care giver benefits the patient, the care giver, and the community
}

Papers pp 1099, 1102

BMJ 2004;328:1085-6
$\mathrm{A}$ $\mathrm{t}$ any time, about $0.5 \%$ of the population of the United Kingdom (250 000 out of 50 million) are disabled stroke survivors who are dependent on the help of a carer to perform community based activities (for example, shopping), domestic activities (housework), and personal activities of daily living (mobilising, toileting, bathing, dressing, grooming, and feeding). ${ }^{1}$ This year, at least another $0.07 \%(35000)$ of the UK population will become disabled stroke survivors seeking full time or part time care. ${ }^{23}$ Such care is generally provided in a nursing home, hostel, or the home of the patient or carer, often after a period of care and rehabilitation in hospital. Additional formal support may sometimes be forthcoming from community nursing services and allied health and social services. But the onus of caring for such patients at home usually falls on one or more informal care givers, who are often family members (usually spouses and children), and sometimes friends. ${ }^{4}$ Two papers in this issue show that providing care givers with training in basic nursing skills is good for the patient, the care givers, and the community (pp 1099, 1102). ${ }^{56}$

Informal care givers aim to meet the needs of the dependent stroke survivor while concurrently adjusting vocationally, socially, and emotionally to the sudden change in their own lifestyle. The needs of the disabled stroke survivor are often multiple and include help with physical activities (for example, moving, handling, and transferring from bed to chair, and chair to toilet); nursing activities (facilitation of activities of daily living such as feeding); communication (verbal and non-verbal interaction with family, friends, and the outside world); psychological and emotional support (to adapt to the effects of the stroke); and social reintegration into society. Carers need to be motivated, enthusiastic, physically fit, psychologically sound, emotionally robust, financially resourceful, and adequately informed, trained, and skilled. Little time may be available between the sudden onset of stroke and discharge from hospital to consider, let along acquire, these attributes.

The consequences of informal care giving can be numerous and cumulative. The altruistic benefits of contributing to the welfare of the stroke survivor and the community can be a rich source of motivation and carer satisfaction. However, with time the chronic burden of physical, psychological, social, and financial stress, coupled with erosion of precious family and leisure time and lack of external recognition and support, contribute to anxiety, depression, and a decline in the quality of life of the care giver. ${ }^{48}$ Furthermore, for couples who were both working before the stroke, the combined loss of income from the stroke survivor and care giver (spouse) often far exceeds the combined remuneration from any government pension for disability and care giving, if available. Yet governments and society continue to benefit economically from not having to provide costly institutional care for these patients. $^{4}$

Because of the prevalence and seriousness of the problem of caregiver burden and stress, several attempts have been made to devise, develop, and evaluate strategies of reducing the burden of informal care giving for dependent stroke survivors. These include the provision of information and education and access to services such as nursing, psychological counselling, emotional support, family support workers, and social workers. ${ }^{9-12}$ Although modest benefits have been realised in some measured emotional, psychological, and social outcomes, care givers have continued to be compromised by physical stress in particular.

Kalra et al have taken the next step and shown by means of a randomised controlled trial that supplementing information and emotional support for informal care givers with specific training in basic nursing skills such as moving and handling, and facilitation of activities of daily living improves the outcome of disabled stroke survivors, informal care givers, and the community. ${ }^{5}$ A higher proportion of disabled stroke survivors achieved independence at an earlier stage, the mood and quality of life of disabled stroke survivors and care givers were improved, and the cost of stroke care was reduced. Whether these results can be generalised beyond middle class suburban United Kingdom and care givers who are motivated, keen, and physically fit needs further study.

The implications of these results, if they can be generalised widely, are that the (inpatient and outpatient) rehabilitation and care of disabled stroke survivors should be broadened to include the proposed care giver in the multidisciplinary rehabilitation team, involving them actively in setting goals, rehabilitation, care, and planning discharge and ensuring they are as adequately trained, supported, and followed as the patient. ${ }^{13}$ Although healthcare business managers may baulk at the perceived additional costs of providing training services for carers, perhaps they can dip into the greater pool of funds that would otherwise be required to provide care in hostels and 
nursing homes and thus help improve the quality of life of disabled stroke survivors and their carers.

\section{Graeme J Hankey consultant}

Stroke Unit, Department of Neurology, Royal Perth Hospital, Box X2213 GPO, Perth, WA 6001, Australia

(gjhankey@cyllene.uwa.edu.au)

Competing interests: None declared.

1 Bonita R, Solomon N, Broad JB. Prevalence of stroke and stroke-related disability: estimates from the Auckland stroke studies. Stroke disability: estimates

2 Sudlow CLM, Warlow CP. Comparable studies of the incidence of stroke and its pathological subtypes. Results from an international collaboration. Stroke 1997;28:491-9.

3 Bamford J, Sandercock PAG, Dennis M, Burn J, Warlow C. A prospective study of acute cerebrovascular disease in the community: the Oxfordshire Community stroke project, 1981-86. 2. Incidence, case fatality rates and overall outcome at one year of cerebral infarction, primary intracerebral and subarachnoid haemorrhage. J Neurol Neurosurg Psychiatry 1990:53:16-22.

4 Dewey HM, Thrift AG, Mihalopoulos C, Carter R, Macdonell RA, McNeil JJ, Donnan GA. Informal care for stroke survivors: results from the North
East Melbourne stroke incidence study (NEMESIS). Stroke 2002:33:102833.

5 Kalra L, Evans A, Perez I, Melbourn A, Patel A, Knapp M, Donaldson N. Training care givers of stroke patients: randomised controlled trial. BMJ 2004;328:1099-101.

6 Patel A, Knapp M, Evans A, Perez I, Kalra L. Training care givers of stroke patients: economic evaluation. BMJ 2004;328:1102-4.

7 Scholte op Reimer WJ, de Haan RJ, Rijnders PT, Limburg M, van den Bos GA. The burden of caregiving in partners of long-term stroke survivors. Stroke 1998;29:1605-11.

8 Dennis M, O'Rourke S, Lewis S, Sharpe M, Warlow C. A quantitative study of the emotional outcome of people caring for stroke survivors. Stroke 1998;29:1867-72.

9 Dennis M, O'Rourke S, Slattery J, Staniforth T, Warlow C. Evaluation of a stroke family care worker: results of a randomised controlled trial. BMJ 1997;314:1071-7.

10 Rodgers H, Atkinson C, Bond S, Suddes M, Dobson R, Curless R. Randomised controlled trial for a comprehensive stroke education programme for patients and caregivers. Stroke 1999;30:2585-91.

11 Mant J, Carter C, Wade DT, Winner S. Family support for stroke: a randomised controlled trial. Lancet 2000;356:808-13.

12 Forster A, Smith J, Young J, Knapp P, House A, Wright J. Information provision for stroke patients and their caregivers. Cochrane Database Syst Rev 2001;(3):CD001919.

13 Legg L, Langhorne P. Rehabilitation therapy services for stroke patients living at home: systematic review of randomised trials. Lancet 2004:363:352-6.

\title{
Roll Back Malaria: a failing global health campaign
}

\author{
Only increased donor support for malaria control can save it
}

$\mathrm{R}$ oll Back Malaria was launched in 1998 bringing together multilateral, bilateral, nongovernmental, and private organisations. It made a clear pledge - to halve deaths from malaria by 2010. African heads of state endorsed the pledge at a summit in Abuja, Nigeria, in 2000. ${ }^{1}$ This endorsement was vital because $90 \%$ of the one million annual deaths from malaria are in Africa, mostly in young children and pregnant women. ${ }^{2}$ With just six years to go we have reached the halfway point since the pledge. How is Roll Back Malaria doing?

A graph distributed at the most recent Roll Back Malaria board meeting in New York, based on data from the World Health Reports 1999-2003, shows that the annual number of deaths worldwide from malaria is higher now than in 1998 (see bmj.com). The Africa Malaria Report 2003, published by Unicef and the World Health Organization, two of the biggest players in Roll Back Malaria, admits that "Roll Back Malaria is acting against a background of increasing malaria burden." This statement is passive, and seems to absolve the campaign of responsibility. A more active statement is thisRoll Back Malaria is currently a failing health initiative.

The question now is whether the campaign can be saved. We have the three tools we need to curb malaria deaths-bed nets, effective combination treatment based on artemisinin, and insecticides. What we urgently need to do is make these tools much more widely available to affected communities, which are almost always too poor to pay for them themselves.

In this issue Molyneux and Nantulya focus on the first of these tools - the distribution of insecticide treated bed nets-a key strategy in the Roll Back Malaria campaign (p 1129). ${ }^{4}$ A systematic review found that such nets are highly effective in reducing childhood mortality and morbidity from malaria. ${ }^{5}$ But even with Roll Back Malaria's best efforts, only about one in seven children in Africa sleep under a net, and only $2 \%$ of children use a net impregnated with insecticide. ${ }^{3}$
Molyneux and Nantulya argue that Roll Back Malaria's scheme for net distribution, in which pregnant women attending antenatal services get vouchers to subsidise the purchase of nets, misses the many women who don't attend such services. And even with a voucher, the cost may be prohibitive. They propose a new "pro-poor" strategy in which the distribution of bed nets is linked to other disease control programmes. Hard to reach communities who are already being reached by these other programmes, such as those to control onchocerciasis and lymphatic filariasis, could at the same time be given bed nets. The authors discuss ways in which controlling other diseases could benefit malaria control-for example, controlling intestinal worms may reduce children's susceptibility to malaria.

Creating linkages between global health initiatives makes intuitive sense, and Molyneux and Nantulya cite evidence of the feasibility of linkage-the successful linkage of distribution of bed nets to a measles vaccination campaign. But this approach should not detract from donors' specific responsibilities towards malaria control. Donors made promises to commit substantial new resources to improve access to bed nets, insecticides, and malaria drugs, and we need to hold them to their promises. ${ }^{1}$ Whatever happened, for example, to the $\$ 500 \mathrm{~m}(£ 282 \mathrm{~m} ; € 420 \mathrm{~m})$ that the World Bank pledged at the Abuja summit? ${ }^{6}$ Many years of AIDS activism, including pressure on donors, has finally seen HIV combination therapy reaching some of the world's poorest countries. What we need now is a new era of "malaria activism" in which we demand that donors massively increase their malaria funding to purchase effective, but currently expensive, artemisin based combination therapies.

A figure showing the effect of malaria is on bmj.com
Education and debate p 1129, News p 1095 